\title{
Statement on approval of training schemes for general professional training for the MRCPsych
}

\section{Organisation \\ 1. Tutors}

Every training scheme must have a tutor(s) who is responsible for the running of the scheme. Rotational training schemes should be administered by a training committee which should include the tutor(s) and an adequate number of representatives of the consultants and other teachers involved, as well as representatives of the trainees themselves.

The tutor needs to have the support of other consultant colleagues. He or she will be appointed at local, regional, university or national level and recognised by the College. A minimum of two sessions per week is required by the tutor to carry out his duties according to the College document on 'Recognition of Psychiatric Tutors and others concerned with the provision of postgraduate psychiatric education and training'. It is important for training scheme organisers to have such designated sessional time; tutors with much smaller training commitments may not require this. The tutor requires adequate opportunity for continuing medical education both in methods of teaching (e.g. Clinical Tutors' Annual Conference) and for the development of the tutor's own psychiatric skills. The tutor should not normally be in post for more than five years consecutively.

\section{Administration of training committee}

It is helpful for the training committee to include a representative of the administration. A good relationship with the administration can facilitate the smooth running of the scheme especially in relation to such matters as accommodation, residence, mileage allowances and extra duty payment. Postgraduate training in psychiatry will be answerable to a Regional Training Committee (or Scottish Training Committee) for the specialty. It is helpful to have, in addition, a regional structure for tutors to meet on a regular basis.

\section{Organisation and administration of trainees}

Trainees should meet together regularly and have some formal or informal committee structure in order to discuss the training programme and to nominate representatives to educational and other administrative committees or working parties. This gives useful experience in administration and management.

\section{Selection of trainees}

The psychiatric tutor, or the tutor's nominee, should always be a member of a properly constituted SHO appointments committee. The selection of suitable trainees is all-important. Only those who are suitable for training should be appointed to the training scheme. Suitable and promising trainees, early in their careers, do not need to be committed to a career in psychiatry at the time of their appointment. Following Achieving a Balance: Plan for Action (1988), registrars are employed by the Regional Health Authority (or the Scottish Training Committee). It will be necessary to have a formal appointments committee for the promotion of SHOs to registrar posts. It is hoped that, for the preservation of integrated training, due consideration will be given to the applications of SHOs already in the scheme who have performed well in post.

\section{Medical stafi}

\section{(a) Consultants}

The supervision and instruction of trainees make considerable demands on the time of all consultants involved, and especially on the tutor. It is therefore essential that the number of consultants available is adequate and in line with the College 'norms', both for general psychiatry and the sub-specialties. There should be sufficient medical staff to ensure that the trainees' access to training experiences is not significantly hampered by a substantial service demand, particularly from long-stay areas.

The educational supervisor. The General Medical Council in its document on basic specialist training has designated the consultant who has junior doctors working with him 'the educational supervisor'. Such a consultant has responsibilities towards his trainee, as well as the advantages of having a junior doctor working with him. It would be reasonable to set aside a period of time each week to be spent by the educational supervisor with the trainee on his/her own, involved in activities that are beneficial to the trainee. If individual patients are discussed this should be for the purpose of training, for example, in interview skills or psychotherapy, and not for the purposes of carrying out executive consultant management. What is discussed in this time would depend upon the individual needs and the stage of training of the trainee but might include the elements of interviewing and talking with patients, practical principles of 
drug prescribing, elementary skills in counselling and psychotherapy, use of the Mental Health Act, relationships with other disciplines, and so on. A more senior trainee might benefit from discussing his or her research with the educational supervisor. This time might be used in many different ways, for example, the trainee might be video-taped with a patient and then discuss the video while watching it with the educational supervisor. The purpose of the whole exercise would be to build in time that belongs to the trainee, and not to the consultant, for the former's sole benefit. It should be time for developing clinical skills and not for theoretical learning. This type of contact between trainee and senior doctor should occur with the consultant with whom he or she is working, that is, the educational supervisor, and not with the clinical tutor whose duties are different.

\section{(b) Junior staff}

Training for the MRCPsych normally requires at least three years' clinical experience in psychiatry, and most training schemes are approved for training of this duration. In general, the most usual arrangement is a rotational scheme in which recruits entering at SHO level have the opportunity of completing their general professional training within the same scheme, subject to satisfactory progress and appointment to the registrar grade. Whenever trainees remain in registrar posts for four years, time should be given to research.

However, the Court of Electors still approves, for a limited period of training, some smaller schemes where such progress is not possible because there are insufficient posts and/or the variety of experience is limited. To be approved, the training in such schemes must be of a high quality in all other respects, apart from the limited variety. Psychiatry deals with a large number of emergencies during the 24 hours and nearly all admissions are acute emergencies. There are at present almost no pre-registration doctors in psychiatry and therefore the 'safety net' (Achieving a Balance: Plan for Action) consists of trainees involved in rotational programmes. The following guidelines should be followed in the planning of 'safety nets'.

1. Psychiatry is a specialty where 24 hour cover is necessary for treating emergencies.

2. 'Safety net' arrangements must be planned for the assessment and treatment of all psychiatric emergencies by psychiatric staff.

3. Cross specialty cover for psychiatric emergencies by trainees in other specialties is not appropriate; nor should psychiatric trainees be involved in cross cover arrangements for specialties other than psychiatry.

4. 'Safety net' arrangements should not interfere with the carefully worked out rotational train- ing programmes of the College and Joint Committee on Higher Psychiatric Training for junior trainees and senior registrars. Therefore:

(a) The College does not regard it as essential that every district providing a 'safety net' should have at least one career registrar. This will generally be the case, but appropriately supervised SHOs in psychiatry, including trainees from other specialties, e.g. general practice vocational trainees, can also be included.

(b) The Joint Committee on Higher Psychiatric Training has specifically stated that senior registrars should not 'act down' as junior trainees on duty rotas but should have experience 'on call'.

\section{Designation of 'training posts'}

Approval is given for junior doctors working in designated training posts in a scheme to prepare themselves for the MRCPsych Examination. Training posts for this purpose are SHO and registrar posts. Under certain circumstances approval may be given on an individual basis for training for the examination of holders of staff grade posts; where such arrangements exist it is important for the post to be reviewed by the Approval Team.

\section{Duration of the scheme}

Since the Membership Examination can normally be taken for the first time only after a minimum of three years' clinical experience, trainees whose progress is satisfactory should be able to remain within these schemes with approval for the full duration of training for a minimum of four years, and up to four and a half, if necessary. It should be borne in mind that in a large rotational scheme, the number and variety of placements will be such that no one trainee will receive every type of experience during his or her period in the scheme.

\section{Duration of attachments}

In general psychiatry, attachments of six to twelve months' duration probably strike the best balance between the needs of training and those of the patients for continuity of care. Attachments should always be of the apprentice type supervised by a consultant and involved in clinical work - not merely observation.

\section{Assessment of trainees and trainers}

(a) Trainees' progress should be regularly assessed by consultants and tutors. While informal discussions are helpful, in addition formal written assessments must be used. During the placement, there should be an opportunity for open 
discussion and access to this report, when trainees can learn how they are performing and modify their work if necessary.

(b) Assessment forms should be used in schemes, and generally cover the following points:

(i) ability in history taking, formulation and oral and written case presentation;

(ii) therapeutic skill and judgement, including ability in specific treatment techniques;

(iii) relationships with patients and their relatives and with colleagues (medical and non-medical);

(iv) theoretical knowledge of psychiatry;

(v) knowledge of, and skill in, general medicine at a level appropriate to a general medical practitioner;

(vi) initiative, reliability, self-reliance and administrative ability;

(vii) communication skills and command of English language.

The written assessments should remain confidential to the trainee, tutor and consultant concerned, but the information thus obtained can be used, at the tutor's discretion, for reviewing both the training programme and the progress and reappointment of trainees. In addition the trainee's views of the teaching received from the consultant and the value of the training post should be obtained. Some schemes use a form specially designed for this purpose.

The tutor should be able to build up a picture, over several rotations, of the quality of training in each training placement. This should be used for improving the training scheme. Individual trainees' comments on individual consultants should not automatically be seen by the consultant concerned but assessments should remain confidential between trainee and tutor. Only if there were a series of adverse comments would the tutor approach the consultant concerned so that a single trainee would not be identifiable.

\section{Type of experience}

In organising an individual trainee's rotation, consideration needs to be taken of his or her previous experience, special needs and interests.

In organising the experience provided by a scheme, these guidelines should be followed:

\section{General psychiatry}

Training should generally be for a minimum period of 12 months initially and 18 months altogether in general adult psychiatry (which may include for not more than half the experience of general psychiatry, the psychiatry of old age, provided there is a variety of patients, including those with functional disorders, in a variety of settings). This must include properly supervised out-patient experience, including both new patients and follow-up cases, and supervised experience of emergencies and 'on-call' duties. An essential for training is acquiring interpersonal skills. The aim is that the trainee should begin to function as a 'good' psychiatrist with appropriate attitudes, knowledge and skills.

Provided there is active consultant participation and supervision, experience in general psychiatry can also be obtained in:

(a) a psychiatric day hospital

(b) a long-stay ward preferably attached to a rehabilitation team

(c) a unit for the care of the elderly, preferably with a consultant with special responsibility for the psychiatry of old age.

Some supervised community experience is necessary, including accompanying on suitable domiciliary visits, home assessments with community nurses or social workers and attachments in general practice. Other experience could include work in a community mental health centre, crisis intervention service, treatment at home, etc.

All trainees should have experience of:

(a) working with community psychiatric nurses, social workers, clinical psychologists, and with other professionals involved with the patient and his or her family

(b) treating patients in mixed sex wards

(c) giving a course of electroconvulsive treatment under conditions approved by the College guidelines.

Trainees in the United Kingdom should have experience of treating patients under compulsory orders of the Mental Health Act and, if possible, attending hearings of Mental Health Review Tribunals.

\section{Substance misuse (alcohol and drug dependence)}

Attention is drawn to the need to ensure that trainees receive adequate experience in this area. Where there is a separately staffed unit or service for the treatment of alcohol and/or drug dependence, it should be possible to offer a whole-time or part-time placement. For this to be regarded as a sub-specialty experience, the trainee must spend at least half his time in a range of methods of managing people with alcohol and drug problems.

\section{Child and adolescent psychiatry}

There should be a significant element of experience in child and adolescent psychiatry at registrar level, either part-time or whole-time. A longer part-time attachment might permit the trainees to follow cases through, but this has to be balanced against the other advantages which accrue from a whole-time attachment. 


\section{Forensic psychiatry}

Experience in forensic aspects of psychiatry should be gained wherever possible, by being directly involved in the clinical care of patients referred to consultants with a special interest or responsibility in forensic psychiatry. It is also valuable for trainees to accompany consultants when patients are seen for medico-legal purposes at prisons, hospitals, (including the Special Hospitals), secure units, remand centres and other establishments. On these occasions trainees may prepare 'shadow' reports which are subsequently discussed with the consultant. Trainees should have access to a course of lectures which introduce them to the main principles of forensic psychiatry and medico-legal work.

\section{Liaison work}

Experience in liaison psychiatry should be gained during training. Opportunities will naturally be greater in district general hospital units than in psychiatric hospitals. All trainees should receive adequate supervised experience in the assessment and management of parasuicide. Other valuable experience might include eating disorders, neuropsychiatry and pregnancy-related disorders.

\section{Mental handicap}

There should be an exposure sufficient to give the trainee an awareness of the nature and scope of the problems. The emphasis should be on psychiatric and psychological treatment rather than on basic physical care. Between three and six months wholetime clinical experience or its equivalent would be desirable. This must include experience outside the hospital - such as in clinics, hostels and homes.

\section{Psychiatry of old age}

Particular importance is attached to experience in this area because of the increasing numbers of elderly people in the population and the high incidence of mental disorder in this group. The psychiatry of old age should constitute a separate attachment within the rotational training scheme where the local arrangements permit, e.g. if there is a consultant with a special responsibility in the psychiatry of old age and/or a psychogeriatric assessment unit. It is important that trainees should gain experience in the acute and functional disorder of the elderly mentally ill and in assessment, rather than being exposed solely to a series of patients with dementia.

\section{Psychotherapy}

Trainees must have supervised training in psychological treatments throughout the training scheme. Attention should be paid to the psychodynamic, cog- nitive and the behavioural therapies and every effort made to ensure that trainees have periods of attachment to a consultant psychotherapist and to a consultant with a special interest in behaviour therapy. It should be possible for all trainees to gain a limited experience in both individual and group psychotherapy under supervision (peripatetic teaching is useful here). This should include the treatment of a small number of patients for varying periods from six months up to three years. Trainees should also have the opportunity to treat some cases using various behavioural techniques under the supervision of an experienced therapist. The importance of experience in the treatment of psychosexual disorders and marital problems is emphasised.

The numbers of consultant psychotherapists are likely to be limited for some time to come. Nonetheless, there are many psychiatrists and other professionals who are skilled and experienced psychotherapists who should be invited to contribute to training. Continuing supervision of training throughout the training scheme should be available to all trainees whether or not the experience of a block placement in a psychotherapy unit exists.

\section{Rehabilitation}

Attachment to a rehabilitation team, with particular emphasis on the care of patients with severe chronic disability, is to be recommended. Such experience should involve not only in-patients, but day care, including day centres and liaison with hostels, supervised lodgings and sheltered workshops.

\section{Research}

There should be opportunities for trainees to undertake or participate in a piece of supervised research. This is always easier to achieve in a setting where consultants are actively involved in research projects. Research supervision and suggestions for small projects, should be available locally or from a nearby academic department.

To receive full approval, a scheme must include a broad experience in general psychiatry and substantial experience in at least four of those itemised under 2-10. The Court of Electors takes particular note of the efforts made to include all available types of local experience into a training scheme, and this might involve useful experience not included on the above list.

Every trainee must have a minimum of one year's experience in general psychiatry and some experience (at least 18 months in a three year training) of those itemised under 2-10 above. For training in psychiatry to be regarded as satisfactory some training in psychological methods of treatment is necessary. However where training has extended on a scheme to four and a half to five years, the trainee should have had placements of a minimum of six months in at 
least three of items 2-10 above including psychiatry of old age and child psychiatry or mental handicap.

It is the view of the Court of Electors that each experience offered must include direct clinical care of patients. The experience as 'student observer', e.g. in child psychiatry and mental handicap, while of some value, is not regarded as an adequate training in the subject.

\section{Types of teaching}

Each scheme should provide a variety of teaching experience. The following list is not regarded as comprehensive:

1. Probably the single most important ingredient of clinical training is regular direct supervision, either individually or in a small group, by the consultant and (where available) senior registrars. (This is also the weakest aspect of many schemes, particularly in Out-Patients, where supervision is often perfunctory or absent). Such supervision should occur at least weekly. In Out-Patient Departments new patients as well as followup patients should be seen and adequately presented to the consultant, preferably in a multiprofessional setting.

2. Ward rounds, where it is hoped that other disciplines will also be involved (at least weekly).

3. Case conferences where the trainee has an opportunity to present and discuss a patient (either directly or by using video tapes) with other consultants or a visiting teacher, weekly (for at least 30 weeks in the year).

4. Teaching of interviewing skills. This is best done as special teaching occasions, with other trainees, early in training, using video tapes, in addition to teaching under $1-3$ above (at least eight sessions).

5. Journal clubs, where trainees have the opportunity to review a piece of published research, with discussion chaired by a consultant or senior registrar (weekly, for not less than 20 weeks in the year). It is important that consultants involved in training are regular attenders at the case conferences and journal club.

6. Systematic course of lectures and/or seminars covering basic sciences and clinical subjects related to general psychiatric training. These are often organised around a local university centre (for at least 30 weeks in the year).

7. Teaching in related subjects. Although basic sciences may be covered by a university-based course, teaching by local professionals is highly desirable. These should include clinical psychologists, social workers, nurses, occupational therapists and health administrators.

8. Peripatetic teaching. Geographical factors make it inevitable that there will always be some relatively isolated psychiatric hospitals and units which cannot provide comprehensive training from their own resources. The introduction of peripatetic teaching is commended, especially in such areas as psychotherapy, through the appointment of consultants with a part-time commitment to teaching in regional psychiatric hospitals. Alternatively, trainees from the periphery could attend, on a regular basis for a limited period, specialist training occasions in academic departments.

9. Familiarity with management issues is increasingly important for psychiatric trainees aspiring to become consultants. Trainees should have some opportunity for involvement in administration (perhaps of the training scheme itself and also at ward or unit level). Opportunities for learning about management should ideally be available.

\section{Special situations}

\section{Relationships between university teaching hospitals and other psychiatric hospitals and units}

All training schemes should have some liaison with a local university department of psychiatry. In some cases, university teaching hospitals lack certain types of clinical experience and a mutually complementary rotation can be set up. Ideally, all trainees should have an opportunity of working in a university teaching hospital, but this is not always possible both for geographical and logistical reasons.

All training schemes should see themselves as 'teaching schemes' and should not rely on a clinical rotation to a university teaching hospital as their only 'academic input'.

University departments, teaching hospitals, and regional centres should be able to offer the following to all schemes:

(a) courses of instruction on a day or half-day release basis

(b) specialised clinical supervision e.g. in psychotherapy

(c) supervision and advice on research projects

(d) regular meetings with all the local psychiatric tutors

(e) teachers to serve on selection committees for new trainees

(f) teachers who will visit local schemes on a regular basis for teaching occasions, such as case conferences and journal clubs.

\section{The district general hospital psychiatric unit}

Some of these units are small and unable in themselves to provide an adequate all-round basic training in psychiatry. Some may provide good experience over a limited field and would qualify for "limited approval' between 6-18 months. In general it is 
better if they link with other training schemes as the experiences in both parts of the scheme are often complementary. Some district general hospitals have developed a wide enough range of local services to provide for a fully approved training scheme which does not include experience in a traditional psychiatric hospital.

\section{Other facilities required}

\section{Medical facilities}

Patients must have access to good medical and surgical facilities and trainees must have the opportunity to liaise with appropriate specialists and laboratorybased staff when investigating and treating physical illnesses of patients under their care.

\section{Library facilities}

All trainees and trainers must have access to a library providing adequate services. The library, which must be under the direction of a qualified librarian, should contain an appropriate stock of books and journals as well as offering loans, inter-library loans, photocopying and other information services.

While such facilities may be offered by larger libraries in the vicinity, it is essential that basic services should be approved on site, i.e. a core collection, loans (including inter-library) and a general information service. Use of other libraries is likely to be arranged by way of the librarian. Formal agreements must be entered into to provide this back-up, including reciprocity.

A basic library should include a minimum of ten psychiatric journals as well as providing access to general medical journals (e.g. British Medical Journal and Lancet). Advice on recommended journals and books can be obtained from the College library. The clinical tutor and College Library Committee would also advise in this area.

Approximately $50 \%$ of the library budget should be allocated to journals and $50 \%$ to books and information services such as inter-library loans and on-line searching.

It should be noted that the provision of a library is a statutory duty of the local Health Authority (Medical Act 1978). See also General Medical Council: Education Committee, Recommendations on the Training of Specialists, 1987 (paragraphs 53 and 68).

\section{Office and consulting room accommodation}

Ideally, every trainee should be provided with his or her personal office. An essential requirement is the provision of an adequate number of rooms in a treatment area where patients and relatives can be interviewed in safety, privacy and comfort. These must be provided both on the wards and in out-patient departments. Such rooms are often unavailable on general medical or surgical wards and special efforts need to be made to provide for privacy and confidentiality when doing 'liaison work'.

All trainees should be provided with sufficient secretarial time to ensure that letters are typed on the day of dictation and discharge summaries received by GPs within a week of a patient's discharge from hospital. Research plays an important part in psychiatric training and it is essential that trainees receive the necessary secretarial support for this.

There should be adequate accommodation for seating up to eight to ten people in comfort, to facilitate the holding of team meetings, and similar activities. Every consultant requires an office, and adequate secretarial support is also essential.

In addition to individual offices, at least one conference room is essential, large enough for all the staff working in the unit. A large psychiatric hospital may need several rooms. It should not be necessary to use any of the patient's accommodation for this purpose but patients could use these out of hours for quiet rooms, receiving visitors, etc.

\section{Accommodation for organised postgraduate activities}

\section{(a) Lecture room}

This should be large enough to accommodate all the psychiatric medical staff together with such numbers of doctors in other specialities and non-medical staff as may be expected to attend meetings. The lecture room should be designed so as to permit the ready use of slide and cine projectors. and any other audiovisual equipment considered necessary. It should have facilities for the safe storage of this equipment.

\section{(b) Seminar room}

This should be less formal in character and suitable for group discussions involving up to 16 persons. More than one seminar room may be necessary. Where it is necessary to share the use of lecture and seminar rooms with other specialties and disciplines the numbers of those sharing should not be so great in relation to the number of rooms available as to make it difficult to arrange meetings, or impossible to do so unless rooms are reserved long in advance.

\section{(c) Video facilities}

With the requirements for training in interview skills for Part I of the MRCPsych examination there should be facilities for using video equipment for such training. Ideally a separate studio should be available but otherwise facilities in a seminar room or lecture room would be acceptable. 


\section{Residential accommodation}

A good standard of psychiatry cannot be practised in a hospital where patients are living in cramped conditions with little privacy and inadequate space for their personal possessions. Approval teams always inspect patients' accommodation, both acute and long-stay.

A good standard of accommodation is equally necessary for trainees. Criteria have been laid down for these (see 'Accommodation for Trainees', appended). To be fully approved, these standards must be reached and adequate facilities for private study provided.

\section{Medical audit}

Medical audit is required as an important part of the work of any district in which training in psychiatry is taking place. This should include surveillance of the standards of case notes, assessment of the quality of patient care, regular audit meetings which should give detailed consideration to untoward events taking place within the service (e.g. suicide and other deaths in hospitals) and case conferences for each consultant in the clinical service. There is also scope for considering audit more formally at district and regional level and for applying the standards on audit that the College is at present preparing. Continuing Medical Education for consultants, that it is available locally and being taken advantage of by consultants who are trainers, should also be seen as part of the process of audit within approved hospitals.

\section{The standard of case records in approved training schemes}

\section{Introduction}

In a clinical discipline, the main vehicle of learning is the detailed study of individual patients. The results of this enquiry are recorded in the case records, which serve as a channel of communication between professionals about the diagnosis and treatment of the patient concerned. The case records are a valuable data source for psychiatric research, may be subpoenaed by the courts and may be used for clinical audit. For all these reasons, therefore, the quality of the records must be high on accredited teaching units, and their standard is one of the criteria by which these units may be judged.

\section{The organisation of the record}

There are several acceptable ways of organising a case record, including:

(a) Organisation by successive admissions, with all information relevant to that admission (correspondence, nursing observations, investigations, reports by social workers, psychologists and occupational therapists, and outpatient follow-up notes), compiled in the same compartment as the in-patient medical notes

(b) organisation by data source, with separate compartments for in-patient admissions, out-patient care, nursing observations, correspondence and investigations

(c) organisation as a consecutive record, all sources being compiled in chronological sequence

(d) organisation in problem-orientated form.

The College would not wish to express a preference for one method of organisation, but rather to stipulate the elements which should always be present in a case record of teaching standards.

Case records should be typed or written legibly.

\section{The contents of case records of teaching standard}

1. The reason for referral (or admission) should be stated with an account of the circumstances and events leading to it.

2. The clinical state should be documented, by an exploration of symptoms and an examination of the physical and mental state.

The exploration of symptoms includes verbatim statements made by the patient about the main complaints together with the answers to clarifying questions about these and related symptoms. It also includes an account of the development of the illness and of the psychiatric history.

The mental state examination includes:

(a) an exploration of the patient's preoccupations and concerns, including his/her self esteem (self-image), hopes, griefs and fears

(b) the review of major psychiatric symptoms such as morbid ideas (content and form), perceptual anomalies and mood disorders

(c) observations about appearance, behaviour, affect, speech and rapport with the interviewer

(d) the testing of cognitive functions including orientation, intelligence, concentration and memory and (in appropriate patients) neuropsychiatric testing.

3. The patient's account of the personal history and clinical state is amplified by corroborative accounts especially from relatives and (for inpatients) nursing staff, who observe behaviour in a variety of settings, and other members of the multidisciplinary team. If the patient has been in psychiatric treatment before, the case records are obtained, studied and summarised.

4. There is an account of the personal history, including the family background, childhood and schooling, work record, psychosexual and marital 
history, health, lifestyle (including deviant behaviour) and present circumstances. If this has already been explored at a previous referral, it is not always necessary to start afresh at the beginning: it may be acceptable and even preferable to update the earlier account by further clarification and exploration of recent events. The personal history pays particular attention to the nature and quality of relationships, especially with the family of origin, partner and children.

5. There must be a consideration by the trainee of diagnosis (assessment), including the differential diagnosis, and treatment (management). The diagnosis, should not be limited to the clinical state, but should include an assessment of personality and social circumstances, with an attempt to clarify the interaction of past and present factors in producing the recent situation. In the best teaching units this discussion will often include the results of reading in the library about the salient features of the patient's illness. The discussion of management should include a plan of further investigation if necessary, and an account of the style and role of psychotherapy and social treatment as well as pharmaceutical treatment, with details of the part to be played by each member of the team.

6. The patient's progress in hospital, out-patients or home treatment is documented by frequent, legible and concise notes. Changes in clinical state and treatment plan are clearly recorded. At the time of discharge, a note is made of the clinical state (comparing it with that present at the height of the episode), and of recommendations for future treatment.

7. Major episodes, whether treated in hospital or at home, are drawn together by a typewritten summary for ease of reference. These summaries may be organised episode by episode or in the form of an overall summary of the whole course of the illness. For patients treated in the out-patient clinic, letters to the general practitioner serve as summaries.

(Approved by the Court of Electors - April 1989)

\section{Accommodation for trainees}

[Recommendations by Committee B of the Medical Whitley Council concerning the type of accommodation to be provided for resident medical officers in grades up to and including Senior Registrars: HM(58)68.]

1. (a) The structure of the residents' quarters should be sound and free from leaks and damp.

(b) The quarters should be as conveniently situated as possible from the point of view of privacy and quiet, and also accessibility to the officer's work.

(c) When there are a number of residents there should be a separate common room of adequate size and suitable furnishings. The common room should not be used as a dining room.

(d) Residents should not have to carry out hospital correspondence or keep hospital papers in their own quarters or common rooms.

2. The resident medical officer's room is his home for the time being, and in it he should be able to relax and study in comfort.

The room should be large enough to allow adequately for, and should have, a $3 \mathrm{ft}$ bed or divan and necessary cupboards and drawers, a writing table and chair, bookcase or book shelves and armchair. The floor should be carpeted and the windows curtained. The room should be in good decorative condition, well lit and a reading/ bedside lamp should be provided. All furniture and fittings should be of reasonable quality and in a good state of repair.

If the size of the room is such as not to make a reasonable bed-sitting room, consideration should be given to providing a separate sitting room.

3. Medical officers' hours of duty are irregular, consequently heating arrangements should be such that, when required, rooms can be as quickly and efficiently heated as possible.

4. It is desirable where practicable that each room should contain a wash-basin with hot and cold running water; in addition there should be adequate washing and shaving facilities, bathrooms and lavatories.

5. A telephone by the bed should be connected to the internal hospital telephone. There should be external telephones readily accessible to the residents' rooms and one in the common room.

6. Domestic services should be adequate and sufficient for cleanliness and comfort.

7. Catering: The majority of resident medical officers work long and irregular hours. It is of great importance that their meals should be adequate and varied, attractively and efficiently served and, within reason, freshly prepared. It may, therefore, be desirable for some separate catering arrangements to be made, especially at night.

8. General: Residents should be encouraged to take an active interest in the accommodation, food and services which they receive. There should be informal machinery for the discussion of their views. If subsequently there are any complaints, there should be arrangements to enable them to make direct representation to the local managers. Residents should be made aware of these arrangements. 